\title{
Prediction of the permeability of antineoplastic agents through nitrile medical gloves by zone classification based on their physicochemical properties
}

Toyohito Oriyama ${ }^{1,2^{*}}$ (D) Takehito Yamamoto ${ }^{2,3}$, Katsuhiko Nara², Yohei Kawano', Katsuyoshi Nakajima², Hiroshi Suzuki ${ }^{2}$ and Takao Aoyama ${ }^{1}$

\begin{abstract}
Background: Permeability of antineoplastic agents through medical gloves is an important factor that must be considered for the appropriate selection of gloves. However, predicting the permeability of antineoplastic agents through medical gloves based on their physicochemical properties remains difficult. Thus, this study aimed to elucidate the relationship between the physicochemical properties and permeability of antineoplastic agents through medical gloves. Additionally, we tried to predict the risk of permeation of antineoplastic agents through medical gloves based on physicochemical parameters.
\end{abstract}

Methods: Ten antineoplastic agents (carboplatin, carmustine, cisplatin, cyclophosphamide, doxorubicin, etoposide, fluorouracil, ifosfamide, oxaliplatin, and paclitaxel) with varying physicochemical properties were investigated, and their permeation rates (PRs) through nitrile medical gloves of varying thicknesses $(0.05,0.07$, and $0.1 \mathrm{~mm})$ were measured using a continuous flow in-line cell device. We also determined the apparent permeation clearance (CLp,app) values of the antineoplastic agents based on their PRs at $240 \mathrm{~min}\left(\mathrm{PR}_{240}\right)$ and assessed the relationship between $\mathrm{CL}_{\mathrm{P}, \text { app }}$ and physicochemical parameters [molecular weight (MW) and logarithm of octanol-water partition coefficient (LogP)].

Results: The $C L_{p, a p p}$ values of the 10 antineoplastic agents through nitrile medical gloves ( $0.05 \mathrm{~mm}$ thickness) were significantly correlated with their MWs, but not their LogP values $(P=0.026$ and 0.39 , respectively; Spearman's rank correlation). This finding indicated that the rates of diffusion of the antineoplastic agents in the glove material showed greater effects on $\mathrm{CL}_{\mathrm{p} \text {,app }}$ than the rates of absorption into the glove surfaces within 240 min of exposure. We then classified the 10 antineoplastic agents into 3 zones (Zone A, high LogP/low MW drugs; Zone B, high LogP/high MW drugs; and Zone C, low LogP) and found that Zones A, B, and C corresponded to high ( $\left.P R_{240}>10 \mathrm{ng} / \mathrm{min} / \mathrm{cm}^{2}\right)$, moderate $\left(\mathrm{PR}_{240}<10 \mathrm{ng} / \mathrm{min} / \mathrm{cm}^{2}\right)$, and low (no detectable permeation) permeation risk, respectively.

(Continued on next page)

\footnotetext{
*Correspondence: oriyama-tky@umin.ac.jp

'Tokyo University of Science, Faculty of Pharmaceutical Sciences, 2641

Yamazaki, Noda, Chiba 278-8510, Japan

2Department of Pharmacy, The University of Tokyo Hospital, Faculty of

Medicine, The University of Tokyo, 7-3-1 Hongo, Bunkyo-ku, Tokyo 113-8655,

Japan

Full list of author information is available at the end of the article
}

(C) The Author(s). 2020 Open Access This article is licensed under a Creative Commons Attribution 4.0 International License, which permits use, sharing, adaptation, distribution and reproduction in any medium or format, as long as you give appropriate credit to the original author(s) and the source, provide a link to the Creative Commons licence, and indicate if changes were made. The images or other third party material in this article are included in the article's Creative Commons licence, unless indicated otherwise in a credit line to the material. If material is not included in the article's Creative Commons licence and your intended use is not permitted by statutory regulation or exceeds the permitted use, you will need to obtain permission directly from the copyright holder. To view a copy of this licence, visit http://creativecommons.org/licenses/by/4.0/. The Creative Commons Public Domain Dedication waiver (http://creativecommons.org/publicdomain/zero/1.0/) applies to the data made available in this article, unless otherwise stated in a credit line to the data. 


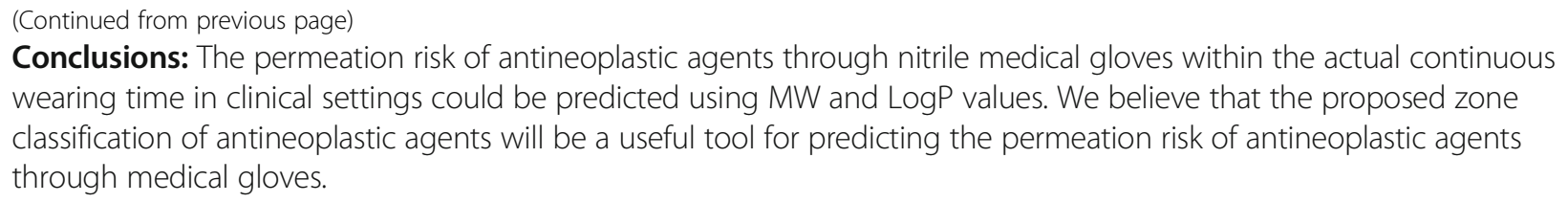

Keywords: Antineoplastic agents, Medical gloves, Permeability, Physicochemical properties, Molecular weight, Nitrile, Zone classification

\section{Background}

Antineoplastic agents are known for their cytotoxic, mutagenic, teratogenic, and carcinogenic properties [1, 2]. Since healthcare professionals are at a very high risk of exposure to antineoplastic agents during the handling process [3-6], appropriate use of safety cabinet, closed system transfer devices, and personal preventive equipment (PPE) is highly recommended [7-11]. Among the various PPE, medical gloves are the most important because they directly protect the hands, which are at a higher risk of exposure to antineoplastic agents during the handling process than other parts of the body including the face, arms, and trunk. However, several antineoplastic agents, such as cyclophosphamide (CPA), carmustine (BCNU), and fluorouracil (5FU), can reportedly penetrate through medical gloves within $240 \mathrm{~min}$, which is the possible continuous wearing time of medical gloves in clinical settings, thereby exposing the hands of healthcare professionals to these drugs [12]. Therefore, evaluating the permeability of antineoplastic agents through medical gloves to predict the risk of exposure is of critical importance.

Several previous reports have shown that the product characteristics of medical gloves (type of material, thickness, and surface treatment) and the physicochemical properties of antineoplastic agents are the major determining factors of permeability of antineoplastic agents through medical gloves [12, 13]. Regarding the product characteristics of medical gloves, it has been reported that nitrile rubber, compared to other materials such as latex, is less permeable. It has also been shown that the permeability of antineoplastic agents through medical gloves is inversely correlated to the thickness of medical gloves. Additionally, our previous report showed that surface treatment of medical gloves altered the permeability of antineoplastic agents [14]. Regarding the effects of the physicochemical properties of antineoplastic agents on permeability, Wallemacq et al (2006) reported that antineoplastic agents with logarithm of octanolwater partition coefficient $(\log \mathrm{P})$ values $>0.5$ tended to exhibit higher permeability through medical gloves than those with $\log \mathrm{P}$ values $<0.5$. However, Wallemacq et al also observed a large variability in the permeability values of the antineoplastic agents with high $\operatorname{LogP}$ values
[12]. The possible contribution of molecular weight (MW) to the permeability of antineoplastic agents has been suggested, but the effects of $\log P$ and $M W$ on the permeability of antineoplastic agents through medical gloves remain to be elucidated. Furthermore, previous reports $[12,13]$ evaluated permeability of antineoplastic agents using permeation rates (PRs) and breakthrough detection time, the time at which PR exceeds the upper limit $\left(10 \mathrm{ng} / \mathrm{min} / \mathrm{cm}^{2}\right)$ determined based on the American Society of Testing and Materials (ASTM) guidelines [15]. This indicated that these previous reports did not include direct evaluation of basic kinetic parameters, such as permeation clearances, because PR also depended on the concentration of antineoplastic agents used in permeation experiments. Thus, considering these observations, we concluded that the effects of physicochemical properties on the permeability of antineoplastic agents through medical gloves remain incompletely understood, making it difficult to predict the permeability of antineoplastic agents through medical gloves based on their physicochemical properties theoretically.

In this study, we aimed to elucidate the relationship between the physicochemical properties and permeation clearances of antineoplastic agents through nitrile medical gloves, which are widely used for handling antineoplastic agents in clinical settings. For this purpose, we conducted permeation experiments using nitrile medical gloves of varying thicknesses and antineoplastic agents with varying physicochemical properties. Furthermore, we proposed a zone classification of antineoplastic agents based on their MWs and $\operatorname{LogP}$ values to enable prediction of the permeability of antineoplastic agents through nitrile medical gloves.

\section{Methods \\ Antineoplastic agents}

Among the antineoplastic agents listed in the ASTM protocol D6978-05 [15], the following 10 antineoplastic agents were selected for this study: carboplatin (CBDCA), BCNU, cisplatin (CDDP), CPA, doxorubicin (DXR) hydrochloride, etoposide (ETP), 5FU, ifosfamide (IFM), oxaliplatin (OXA), and paclitaxel (PTX). CBDCA, CDDP, CPA, DXR hydrochloride, ETP, 5FU, IFM, PTX, and OXA were obtained as pharmaceutical products, 
while BCNU was purchased from Sigma-Aldrich (St. Louis, MO, USA) since BCNU has not been approved as an injection in Japan (Table 1).

For use in the experiments, CPA, DXR hydrochloride, and IFM were absorbed in normal saline, while CBDCA, CDDP, ETP, 5FU, OXA, and PTX solutions were used directly. BCNU was absorbed in dehydrated alcohol (33 $\mathrm{mg} / \mathrm{mL}$ ) and further diluted 10-fold (v/v) with water for injection (Otsuka Pharmaceutical Co., Ltd. Tokyo, Japan) to obtain a final concentration of $3.3 \mathrm{mg} / \mathrm{mL}$.

The concentrations of the test solutions used for the permeation experiments $\left(C_{\text {Test }}, \mathrm{mg} / \mathrm{mL}\right)$ and the $\mathrm{MWs}$ and $\log P$ values of the 10 antineoplastic agents are summarized in Table 1 [16-22].

\section{Medical gloves}

Nitrile rubber medical gloves of three different thicknesses $(0.05,0.07$, and $0.10 \mathrm{~mm})$ were used in this study. All medical gloves were kindly supplied by Okamoto Industries, Inc. (Tokyo, Japan) after inspection of their thicknesses. The allowance range of thickness was set at specified values $\pm 0.03 \mathrm{~mm}$.

\section{Permeation experiments}

The permeation experiments were performed using an ILC14 continuous flow in-line cell (PermeGear Inc., Hellertown, PA, USA) by the same method described in our previous report [14]. The area of the medical gloves in contact with the antineoplastic agents was $1 \mathrm{~cm}^{2}$, and the surface temperature was maintained at $27^{\circ} \mathrm{C}$ throughout the experiment following the recommendations of the F739-07 protocol [23]. The receptor solution (purified water) was pumped at a flow rate of $1 \mathrm{~mL} / \mathrm{min}$. After adding the antineoplastic agent solution $(1 \mathrm{~mL})$ onto the upper side of the medical gloves, the receptor solutions were collected for $0-15,15-30,30-60,60-$ 120 , and $120-240 \mathrm{~min}$. Specimens $(0.2-0.5 \mathrm{~mL}$ aliquots) were then transferred into polypropylene sample tubes and stored at $-80{ }^{\circ} \mathrm{C}$ until the assay was performed.

\section{Analytical procedure}

All assays were consigned to Shionogi Pharma CO., Ltd. (Osaka, Japan). CPA, DXR hydrochloride, ETP, 5FU, IFM, and PTX concentrations in the specimens were measured by ultra-performance liquid chromatographytandem mass spectroscopy. Inductively coupled plasmamass spectrometry was applied to measure CBDCA, CDDP, and OXA concentrations in the specimens. $\mathrm{BCNU}$ concentrations in the specimens were measured by high-performance liquid chromatography-ultraviolet detection.

The limits of quantitation (LOQs, ng/mL) were as follows: CBDCA, 0.95; CDDP, 0.77; CPA, 0.06; DXR 30; ETP, 12; 5FU, 0.3; IFM, 0.03; PTX, 30; OXA, 1.02; and $\mathrm{BCNU}, 150$. Under our experimental conditions, the LOQs could be converted into PRs $\left(\mathrm{ng} / \mathrm{min} / \mathrm{cm}^{2}\right)$, which were as follows: CBDCA, 0.016; CDDP, 0.013; CPA, 0.001; DXR, 0.5; ETP, 0.2; 5FU, 0.005; IFM, 0.0005; PTX, 0.5; OXA, 0.017; and BCNU, 2.5 .

Table 1 Antineoplastic agents used in this study

\begin{tabular}{|c|c|c|c|c|c|}
\hline Antineoplastic agents & Brand name & $\mathrm{C}_{\text {Test }}(\mathrm{mg} / \mathrm{mL})$ & $M W^{a)}$ & $\log \mathrm{P}^{\mathrm{b})}$ & Ref. $^{\left({ }^{c}\right)}$ \\
\hline Carboplatin & $\begin{array}{l}\text { PARAPLATIN® INJECTION } \\
\text { (Bristol-Myers Squibb K.K.) }\end{array}$ & 10 & 371.25 & -0.46 & [16] \\
\hline Carmustine & $\begin{array}{l}\text { Carmusutin ( } \geq 98 \% \text { ) } \\
\text { (Sigma-Aldrich) }\end{array}$ & 3.3 & 214.06 & 1.53 & [17] \\
\hline Cisplatin & $\begin{array}{l}\text { Randa }^{\oplus} \text { Inj. } 10 \text { mg/20 mL } \\
\text { (Nippon Kayaku Co., Ltd.) }\end{array}$ & 0.5 & 300.5 & -2.19 & [17] \\
\hline Cyclophosphamide monohydrate & $\begin{array}{l}\text { Endoxan }^{\circledast} 100 \mathrm{mg} \\
\text { (Shionogi \& Co., Ltd.) }\end{array}$ & 20 & $261.1^{\mathrm{d})}$ & 0.6 & {$[17]$} \\
\hline Doxorubicin Hydrochloride & $\begin{array}{l}\text { ADRIACIN } \text { Injection } 10 \\
\text { (Aspen Japan Co., Ltd) }\end{array}$ & 10 & $543.5^{\mathrm{e})}$ & 1.4 & [18] \\
\hline Etoposide & $\begin{array}{l}\text { Lastet }^{\oplus} \text { Inj. } 100 \text { mg/5 mL } \\
\text { (Nippon Kayaku Co., Ltd.) }\end{array}$ & 20 & 588.6 & 0.6 & [17] \\
\hline Fluorouracil & $\begin{array}{l}\text { 5-FU Injection } 250 \text { Kyowa } \\
\text { (Kyowa Hakko Kirin Co., Ltd.) }\end{array}$ & 50 & 130.8 & -1.0 & [19] \\
\hline Ifosfamide & $\begin{array}{l}\text { Ifomide } \\
\text { (Shionogi \& Co., Ltd.) }\end{array}$ & 40 & 261.09 & 0.86 & {$[20]$} \\
\hline Oxaliplatin & $\begin{array}{l}\text { ELPLAT }{ }^{\oplus} \text { I.V.INFUSION SOLUTION } 100 \text { mg } \\
\text { (Yakult Honsha Co.,Ltd.) }\end{array}$ & 5 & 397.29 & -1.6 & [21] \\
\hline Paclitaxel & $\begin{array}{l}\text { TAXOL }{ }^{\oplus} \text { INJECTION } 30 \mathrm{mg} \\
\text { (Bristol-Myers Squibb K.K.) }\end{array}$ & 6 & 853.9 & 3.7 & [22] \\
\hline
\end{tabular}

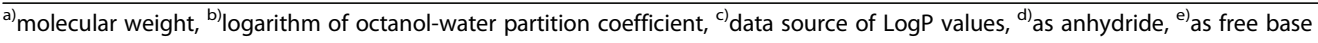




\section{Evaluation of permeability}

Permeation of antineoplastic agents through nitrile medical gloves was evaluated using their PRs, according to the ASTM protocol D6978-05. PR was calculated at each defined time point using the following formula [23]:

$$
\mathrm{PR}\left(\mathrm{ng} / \mathrm{min} / \mathrm{cm}^{2}\right)=(\mathrm{C} \times \mathrm{V}) / \mathrm{t} / \mathrm{S}
$$

where $\mathrm{C}, \mathrm{V}, \mathrm{t}$, and $\mathrm{S}$ represent the concentration of the antineoplastic agent in the receptor solution $(\mathrm{ng} / \mathrm{mL})$, the volume of the collected receptor solution $(\mathrm{mL})$, the exposure time $(\mathrm{min})$, and the area of the glove surface exposed to the antineoplastic agent $\left(1.0 \mathrm{~cm}^{2}\right)$, respectively.

The apparent permeation clearance of each antineoplastic agent at $240 \mathrm{~min}\left(\mathrm{CL}_{\mathrm{P} \text {,app }}\right)$ was calculated using the following formula:

$$
\mathrm{CL}_{\mathrm{P}, \mathrm{app}}\left(\mu \mathrm{L} / \mathrm{min} / \mathrm{cm}^{2}\right)=10^{-3} \times \mathrm{PR}_{240} / \mathrm{C}_{\text {Test }}
$$

where $\mathrm{PR}_{240}$ represents the PR at $240 \mathrm{~min}$ from the start of the permeation experiment $\left(\mathrm{ng} / \mathrm{min} / \mathrm{cm}^{2}\right)$ and $C_{\text {Test }}$ is the concentration of the test solution $(\mathrm{mg} / \mathrm{mL})$. In this study, $\mathrm{CL}_{\mathrm{P} \text {,app }}$ was used as the surrogate indicator for assessing the intrinsic permeation clearance of antineoplastic agent, which is not affected by $\mathrm{C}_{\text {Test }}$.

\section{Statistical analysis}

Spearman's rank correlation was applied to compare the $\mathrm{CL}_{\mathrm{P} \text {,app }}$ values of the antineoplastic agents through nitrile gloves of varying thicknesses and examine the correlation of $C L_{P, \text { app }}$ with $\mathrm{MW}$ and $\log \mathrm{P}$. In all the statistical analyses, $P<0.05$ was considered statistically significant.

\section{Results}

Relationship between permeability of the antineoplastic agents and glove thickness

PRs of the 10 antineoplastic agents through nitrile gloves of varying thicknesses are shown in Fig. 1. High PRs (> $10 \mathrm{ng} / \mathrm{min} / \mathrm{cm}^{2}$ ) of CBDCA, BCNU, CPA, 5FU, and IFM through nitrile gloves $(0.05 \mathrm{~mm}$ thickness) were observed within 240 min of exposure. Among these, BCNU, 5FU, and IFM exhibited thickness-dependent decrease in PR. Limited but detectable PRs $\left(<10 \mathrm{ng} / \mathrm{min} / \mathrm{cm}^{2}\right)$ of ETP and PTX were observed. Like BCNU, 5FU, and IFM, ETP and PTX also showed thickness-dependent decrease in PR. On the other hand, CDDP, DXR, and OXA exhibited no detectable permeation through nitrile gloves of any thickness at any time point.

As shown in Fig. 2, the $\mathrm{CL}_{\mathrm{P} \text {,app }}$ values of the antineoplastic agents through nitrile gloves were increased with the increase in glove thickness ( $R s=-0.37, P=0.047$, Spearman's rank correlation).
Relationship between the permeation clearances and physicochemical properties of antineoplastic agents $\mathrm{CL}_{\mathrm{P} \text {,app }}$ values of the 10 antineoplastic agents through nitrile medical gloves $(0.05 \mathrm{~mm}$ thickness $)$ were plotted against their MWs [Fig. 3(a)] and LogP values [Fig. 3(b)]. As shown in Fig. 3(a), significant negative correlation between $\mathrm{CL}_{\mathrm{P} \text {,app }}$ and $\mathrm{MW}$ was observed $(P=0.026$, Rs $=$ -0.69 , Spearman's rank correlation). In contrast, no significant correlation between $\mathrm{CL}_{\mathrm{P} \text {,app }}$ and $\log \mathrm{P}$ was observed $(P=0.39$, Rs $=0.31$, Spearman's rank correlation).

\section{Discussion}

The results of this study revealed that MW was the crucial determining factor of permeability of antineoplastic agents through nitrile medical gloves within the possible continuous wearing time of medical gloves in clinical settings $(<240 \mathrm{~min})$. Further, we revealed that the permeability of even the antineoplastic agents with high liposolubility could change based on the MWs. Using these findings, we proposed a zone classification of antineoplastic agents based on their MWs and $\log \mathrm{P}$ values to predict permeability through nitrile medical gloves.

As shown in Fig. 1, there was a large variability in the PRs of the 10 antineoplastic agents. Additionally, the slopes of PR against time for five antineoplastic agents (BCNU, ETP, 5FU, IFM, and PTX) with detectable permeation through nitrile gloves of more than one thickness tended to decrease with the increase in glove thickness (Fig. 1). Further, the $\mathrm{CL}_{\mathrm{P} \text {,app }}$ values, which were calculated from the $\mathrm{PR}_{240}$ values using Formula-1, were significantly decreased on increasing the medical nitrile glove thickness (Fig. 2). These observations indicated that two mechanisms (absorption and diffusion) were involved in the permeation of antineoplastic agents through medical gloves. To penetrate through medical gloves, antineoplastic agents are absorbed into the medical gloves. Then, the absorbed antineoplastic agents diffuse in the glove material depending on the concentration gradient. Finally, the antineoplastic agents are released into the receptor chamber (Fig. 4). In this study, we set the duration of the permeation experiment to $240 \mathrm{~min}$, which was the possible continuous wearing time of medical gloves in routine clinical settings. However, the PRs of CPA, ETP, IFM, and PTX continued to increase in a time-dependent manner at $240 \mathrm{~min}$ (Fig. 1), indicating that the permeation process did not reach a steady state. Because PRs are limited to the lesser of absorption rate and diffusion rate, this observation suggests that either the absorption rate or the diffusion rate limits the PRs of these four antineoplastic agents. Theoretically, antineoplastic agents with high liposolubility (i.e., with high $\log \mathrm{P}$ ) exhibit rapid absorption into glove material; therefore, the PRs of PTX $(\log P=3.7)$ would be limited by the diffusion rate. In contrast, the PRs of CPA 
$\begin{array}{ll}\text { (a) CBDCA } & \text { (b) BCNU }\end{array}$

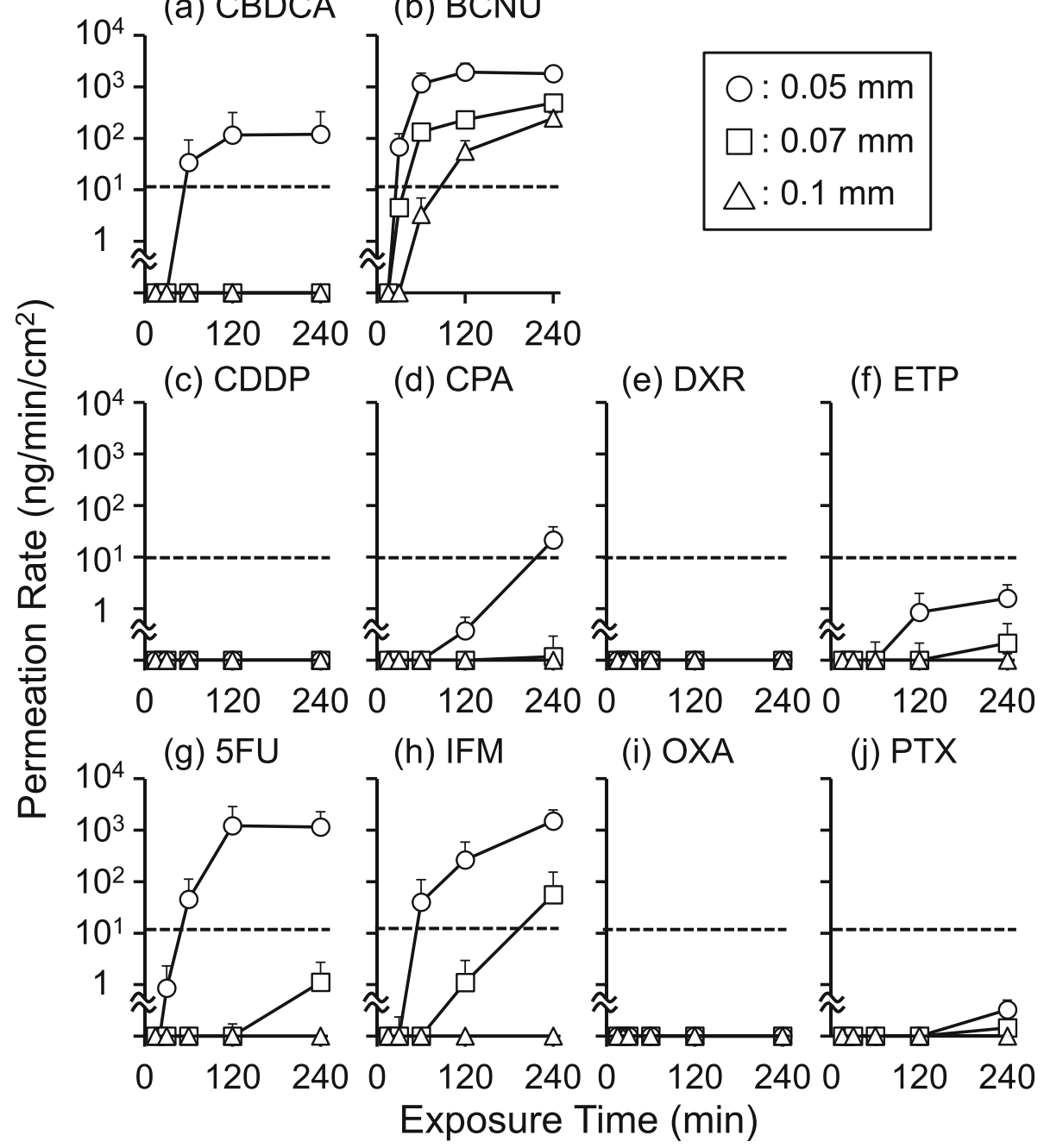

Fig. 1 Permeation rates (PRs) of the 10 antineoplastic agents through nitrile gloves of varying thicknesses. The PRs of the 10 antineoplastic agents through nitrile medical gloves are shown. $\mathbf{a}$-j correspond to carboplatin (CBDCA), carmustine (BCNU), cisplatin (CDDP), cyclophosphamide (CPA), doxorubicin (DXR), etoposide (ETP), fluorouracil (5FU), ifosfamide (IFM), oxaliplatin (OXA), and paclitaxel (PTX), respectively. The symbols and bars indicate mean and standard deviation (SD), respectively $(n=3)$. Open circles, open squares, and open triangles indicate the data obtained using nitrile gloves of $0.05,0.07$, and $0.1 \mathrm{~mm}$ thicknesses, respectively. The dotted line indicates the PR upper limit $\left(10 \mathrm{ng} / \mathrm{min} / \mathrm{cm}^{2}\right) \mathrm{determined}$ based on the American Society of Testing and Materials D6978-05 guidelines. Throughout the permeation experiment, CDDP, DXR, and OXA were not detected in the receptor solution

$(\log \mathrm{P}=0.6), \quad$ IFM $(\log \mathrm{P}=0.86)$, and ETP $(\log \mathrm{P}=0.6)$ would be limited by the absorption rate.

Assuming that antineoplastic agents could diffuse in the glove material by simple diffusion, PRs normalized by $C_{\text {Test }}$ values, namely permeation clearances, were expected to be negatively correlated with MWs. As shown in Fig. 3(a), significant negative correlation between the $\mathrm{CL}_{\mathrm{P} \text {,app }}$ values (calculated using Formula-1) through nitrile medical gloves $(0.05 \mathrm{~mm}$ thickness $)$ and MWs of the 10 antineoplastic agents was observed $(P=0.026$, Spearman's rank correlation), indicating that the $\mathrm{CL}_{\mathrm{P} \text {,app }}$ values of the antineoplastic agents were affected by the diffusion rates under our experimental conditions. As shown in Fig. 1(b), though PR of BCNU through gloves of $0.05 \mathrm{~mm}$ thickness remained almost constant (approximately $1800 \mathrm{ng} / \mathrm{min} / \mathrm{cm}^{2}$ ) $60 \mathrm{~min}$ after the start of the permeation experiment, PRs through gloves of 0.07 and $0.1 \mathrm{~mm}$ thickness continued to increase in a timedependent manner even $240 \mathrm{~min}$ after the start of the permeation experiment. Since nitrile medical gloves used in this study were the same except for their thicknesses, the observed time lag in PR possibly reflected the difference in the time required for $\mathrm{BCNU}$ to diffuse in the glove material. Indeed, Phalen et al (2020) conducted permeation experiments using organic compounds \{cyclohexane $(\log \mathrm{P}=3.44, \quad \mathrm{MW}=84.16) \quad$ [17], tertbutanol $(\log \mathrm{P}=0.35, \mathrm{MW}=74.12)$ [24], and cyclohexanol $(\log \mathrm{P}=1.23, \mathrm{MW}=100.16)[17]\}$ and nitrile gloves 


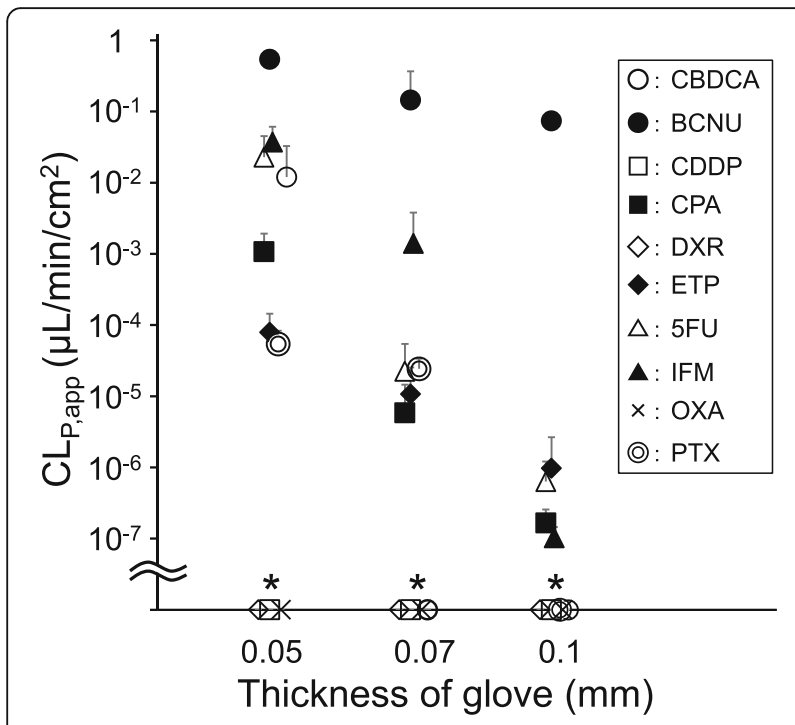

Fig. 2 Relationship between apparent permeation clearance $\left(C L_{p, a p p}\right)$ values of the antineoplastic agents and glove thickness. The $C L_{p, a p p}$ values of the 10 antineoplastic agents through medical gloves of three different thicknesses $(0.05,0.07$, and $0.1 \mathrm{~mm})$ are shown. The symbols and bars indicate mean and standard deviation (SD), respectively. The symbols on the horizontal axis (indicated with an asterisk) indicate the data of antineoplastic agents that were not detected in the receptor solution throughout the permeation experiments. Statistically significant negative correlation between $C L_{p, \text { app }}$ and nitrile glove thickness was observed (Rs $=-0.37, P=$ 0.047, Spearman's rank correlation coefficient)

of varying thicknesses and found that the time required to observe detectable permeation of the organic compounds continued to increase on increasing the nitrile glove thickness [25]. Interestingly, the PRs of organic compounds at a steady state were not significantly affected by the nitrile glove thickness. Considering these data, it was indicated that the diffusion rates of antineoplastic agents largely affected the apparent permeation of antineoplastic agents through medical gloves within 4 $h$ of exposure, and thus, the MWs, which affected the diffusion rates, were significant for determining the risk of permeation of antineoplastic agents through medical gloves.

On the other hand, no statistically significant correlation between $\mathrm{CL}_{\mathrm{P} \text {,app }}$ through nitrile medical gloves (0.05 mm thickness) and $\log \mathrm{P}$, which reportedly affected the permeability, was observed [12] $(P=0.39$, Spearman's rank correlation) [Fig. 3(b)]. As shown in Fig. 3(b), antineoplastic agents with very low $\operatorname{LogP}$ values, including CDDP $(\log \mathrm{P}=-2.19, \mathrm{MW}=300.5)$ and OXA $(\log \mathrm{P}=-$ 1.6, $\mathrm{MW}=397.29$ ), exhibited no detectable permeation $\left(C L_{P, a p p}=0\right)$ through nitrile medical gloves, and this observation was consistent with the results of previous reports [12]. This could be attributed to the low absorption rates of CDDP and OXA due to very low $\log P$ values. However, among the 10 antineoplastic agents,

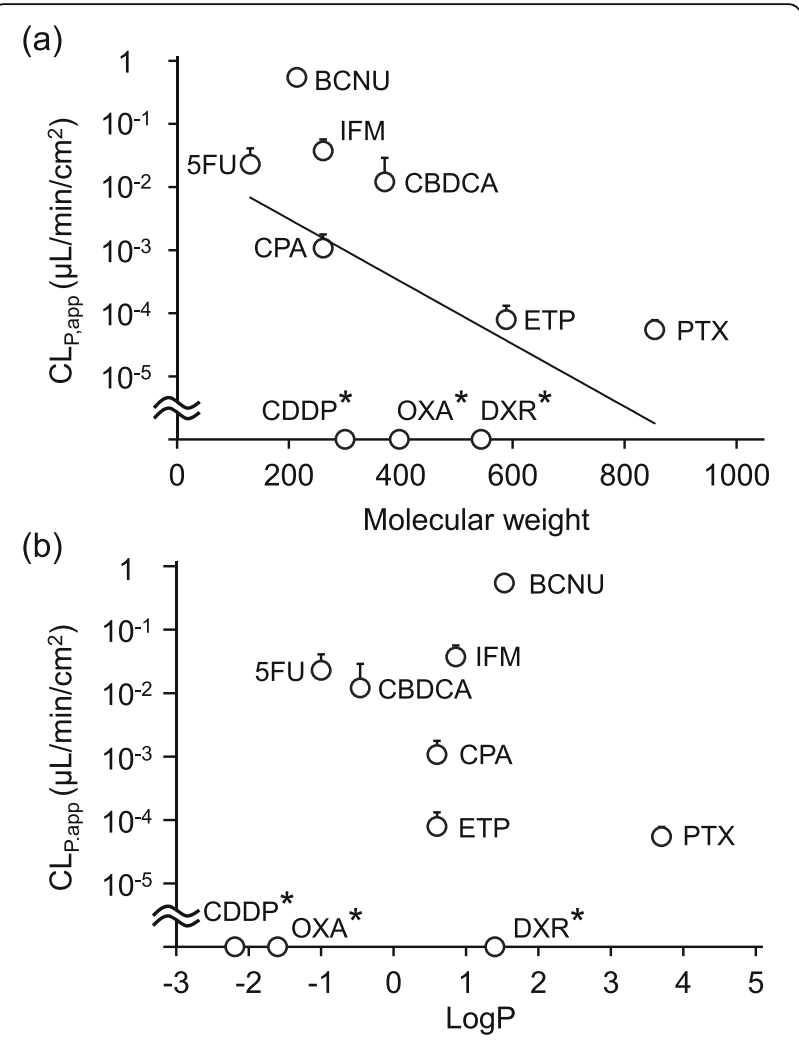

Fig. 3 Relationship between the apparent permeation clearance $\left(C_{p, a p p}\right)$ values and physicochemical properties of antineoplastic agents. The relationships between $C L_{p}$,app of antineoplastic agents through nitrile medical gloves (0.05 $\mathrm{mm}$ thickness) and molecular weight (MW) [panel (a)] and logarithm of octanol-water partition coefficient (LogP) [panel (b)] are shown. Symbols and bars indicate mean and standard deviation (SD), respectively. A statistically significant negative correlation between $C L_{p, a p p}$ and MW was observed ( $P=0.026$, Spearman's rank correlation coefficient). In contrast, no statistically significant correlation between $C_{L p, a p p}$ and LogP was observed ( $P=0.39$, Spearman's rank correlation coefficient). Since cisplatin, doxorubicin, and oxaliplatin (indicated with an asterisk) were not detected in the receptor solution at 240 min from the start of the permeation experiments, $C L_{p}$,app values of these antineoplastic agents were calculated as zero

5FU $(\log \mathrm{P}=-1, \mathrm{MW}=130.8)$ exhibited the third highest $\mathrm{CL}_{\mathrm{P} \text {,app }}$ value $(0.0228 \mu \mathrm{L} / \mathrm{min})$ in spite of exhibiting a low $\log \mathrm{P}$ value. In contrast, $\mathrm{DXR}(\log \mathrm{P}=1.4, \mathrm{MW}=$ 543.5) exhibited no detectable permeation through nitrile medical gloves, even though it exhibited the third highest $\log \mathrm{P}$ value. Although the underlying mechanisms of these inconsistencies observed with 5FU and DXR were unclear, they could be attributed to the diffusion rates of $5 \mathrm{FU}$ and DXR. Considering the very low MW of 5FU (130.8), diffusion rate was expected to be high. Thus, once 5FU was absorbed into the glove material, it could easily and quickly be diffused in the glove material due to its low MW and released into the receptor chamber due to its low solubility. On the other hand, considering the high MW of DXR (543.5), diffusion rate 


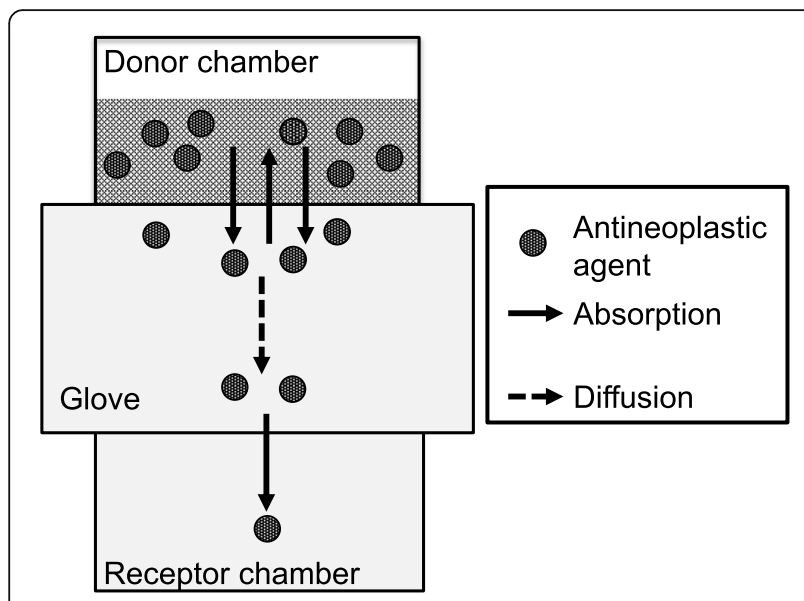

Fig. 4 A schematic diagram of the permeation mechanism of antineoplastic agents through nitrile medical gloves. Two mechanisms (absorption and diffusion) were involved in the permeation of antineoplastic agents through medical gloves. After adding the antineoplastic agent solutions onto the upper side of the medical gloves, antineoplastic agents were absorbed into the interface between the glove material and the antineoplastic agent solution. Then, the absorbed antineoplastic agents were diffused in the medical glove material depending on the concentration gradient. Finally, antineoplastic agents were released from the interface between the glove material and receptor solution. Assuming that the diffusion rate constant of antineoplastic agents in the glove material was low, the concentration of the antineoplastic agent in vicinity of the interface between the glove material and receptor solution would increase slowly after the start of the permeation experiments. Thus, permeation rates (PRs) and apparent permeation clearance $\left(C L_{p, a p p}\right)$ values also increased in a timedependent manner until diffusion reached an equilibrium state. This indicats that $C L_{p, a p p}$ would depended on the diffusion rate constant, which depends on the molecular weight (MW). After diffusion reached an equilibrium state (i.e., after the concentration of the antineoplastic agent in the glove material was uniformized), $C L_{p, a p p}$ would be no longer time-dependent, but instead absorption rate constant-dependent

was expected to be low. Although DXR could be easily absorbed into the glove material due to its high $\log P$ value, absorbed DXR could hardly diffuse in the glove material due to its low diffusion rate, and as a result, DXR exhibited no detectable permeation. In other words, the relationship between $\log P$ and $C L_{P \text {,app }}$ was much weaker than that between $\mathrm{MW}$ and $\mathrm{CL}_{\mathrm{P} \text {,app }}$ under our experimental conditions, making it difficult to detect the statistically significant correlation between $\log \mathrm{P}$ and $\mathrm{CL}_{\mathrm{P} \text {,app }}$ in this study.

Then, we tried to predict the risk of permeation of the antineoplastic agents through nitrile medical gloves based on their MWs and $\operatorname{LogP}$ values. For this purpose, we divided the 10 antineoplastic agents into 3 zones: Zone $\mathrm{A}$, high $\log \mathrm{P} /$ low MW drugs $(\log \mathrm{P} \geq-1$ and $\mathrm{MW}$ $\leq 500)$; Zone $\mathrm{B}$, high $\log \mathrm{P} /$ high MW drugs $(\log \mathrm{P} \geq-1$ and $\mathrm{MW}>500)$; and Zone $\mathrm{C}$, $\operatorname{low} \log \mathrm{P}$ drugs $(\log \mathrm{P}<-$ 1). The $\log P$ and MW boundaries ( -1 and 500, respectively) were set based on the appearance of the data plot. As shown in Fig. 5, Zones A, B, and C clearly corresponded to high $\left[\mathrm{PR}_{240}\right.$ exceeds the upper limit (10 $\mathrm{ng} / \mathrm{min} / \mathrm{cm}^{2}$ ) determined based on the ASTM guidelines], moderate $\left(\mathrm{PR}_{240}<10 \mathrm{ng} / \mathrm{min} / \mathrm{cm}^{2}\right.$ ), and low (no detectable permeation) permeation risk, respectively. The rationale of the zone classification (Fig. 5) is demonstrated in Fig. 6. As shown in Figs. 5 and 6, the Zone A antineoplastic agents demonstrated considerable permeation risk, whereas Zone $\mathrm{C}$ antineoplastic agents demonstrated limited permeation risk. On the other hand, Zone B antineoplastic agents demonstrated low permeation risk, but the risk could increase if the exposure time was prolonged. Interestingly, no significant correlation was observed between $C L_{P, a p p}$ and $\log P$ when the analysis was limited to Zone A (Rs $=0.60, P=0.29$, Spearman's rank correlation) or when all antineoplastic agents were included ( $\mathrm{Rs}=0.31, P=0.39$, Fig. 3(b)); however, Rs values tended to increase when analysis was limited to Zone A. These results suggest that the PRs of antineoplastic agents classified in Zone A (low MW, high $\log \mathrm{P})$ are affected by the absorption rate to some extent and are consistent with the scheme shown in

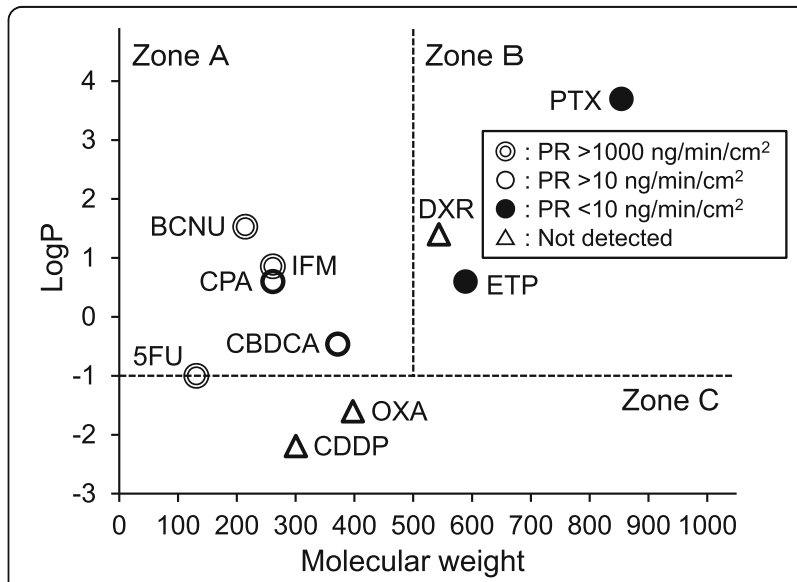

Fig. 5 Prediction of the permeation risk of antineoplastic agents through nitrile medical gloves by zone classification. Zone classification of antineoplastic agents based on their molecular weights (MWs) and logarithm of octanol-water partition coefficient (LogP) values proposed to evaluate the risk of permeation through nitrile gloves is shown. The LogP and MW boundaries were set at -1 and 500 Da, respectively, based on the appearance of the data plot. Each antineoplastic agent was plotted with a different symbol according to their permeation rates at $240 \mathrm{~min}$ ( $\mathrm{PR}_{240}$ values) (see keys in the figure). All "Zone A" ( LogP $\geq-1$ and $M W \leq 500 \mathrm{Da}$ ) antineoplastic agents exhibited high $\mathrm{PR}_{240}$ values that exceeded the upper limit $\left(10 \mathrm{ng} / \mathrm{min} / \mathrm{cm}^{2}\right)$ determined according to the American Society of Testing and Materials D6978-05 guidelines. In contrast, the $\mathrm{PR}_{240}$ values of antineoplastic agents classified in "Zone B" (LogP $\geq-1$ and MW > 500 Da) were lower than $10 \mathrm{ng} / \mathrm{min} / \mathrm{cm}^{2}$ (No detectable permeation was observed for doxorubicin). For oxaliplatin and cisplatin, which were classified in "Zone C" (LogP $<-1)$, no detectable permeation was observed $240 \mathrm{~min}$ after the start of the permeation experiments 


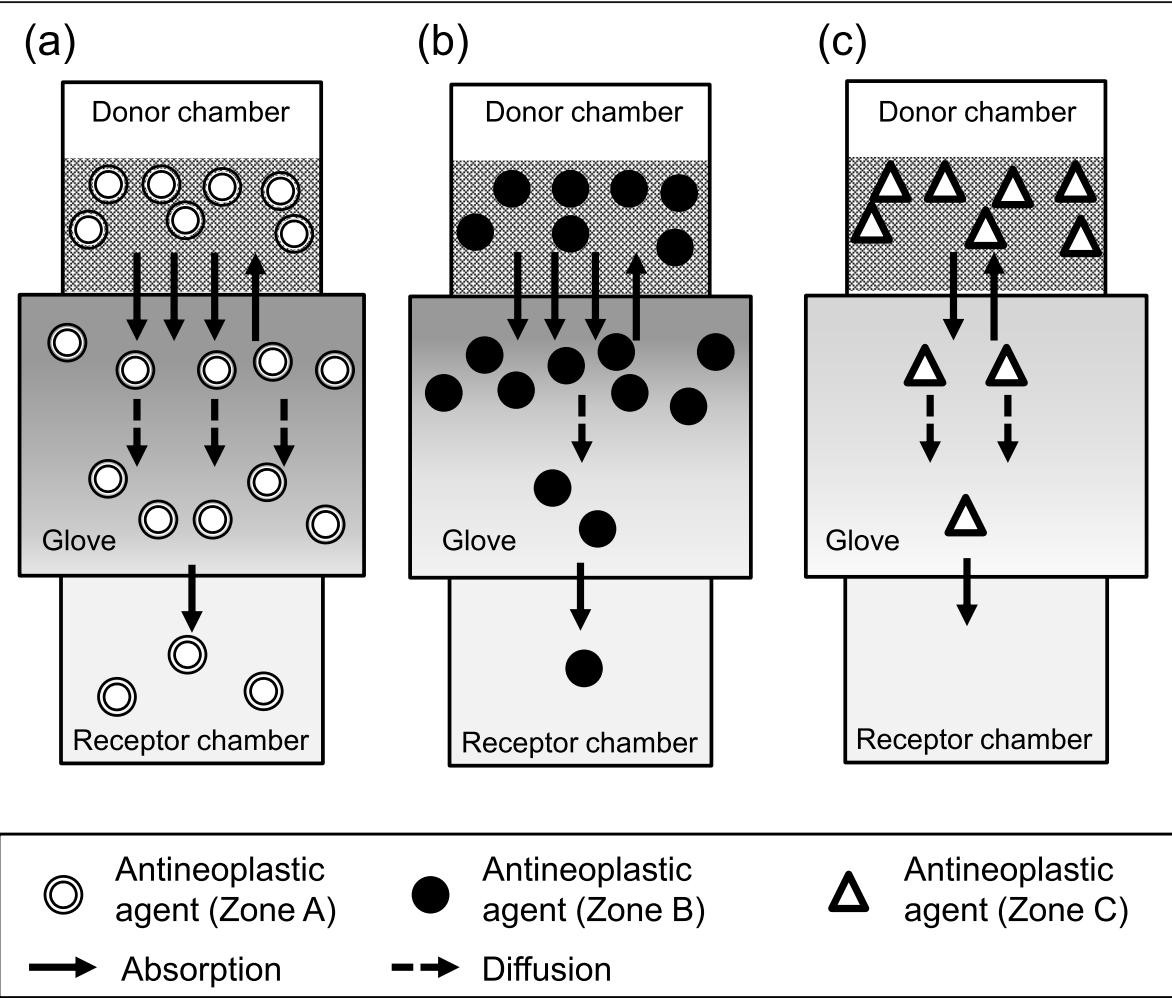

Fig. 6 Schematic diagrams of behavior of antineoplastic agents in nitrile medical gloves. The behavior of antineoplastic agents during permeation through nitrile medical gloves is demonstrated. $\mathbf{a}, \mathbf{b}$ and $\mathbf{c}$ correspond to antineoplastic agents classified in Zones A, B, and C, respectively. Since Zone A antineoplastic agents could be easily absorbed into the glove material and easily diffuse to the interface between the glove material and receptor solution, permeation rates at $240 \mathrm{~min}$ ( $\mathrm{PR}_{240}$ values) were expected to be high [panel (a)]. In contrast, although Zone $\mathrm{B}$ antineoplastic agents could be easily absorbed into the glove material, their rates of diffusion in the glove material were expected to be low due to their high molecular weights (MWs). Thus, $\mathrm{PR}_{240}$ values were also expected to be low [panel (b)]. Zone $C$ antineoplastic agents could not be easily absorbed into the glove material due to their low logarithm of octanol-water partition coefficient (LogP) values; thus, $\mathrm{PR}_{240}$ values were expected to be low irrespective of their MWs [panel (c)]

Fig. 6(a). To the best of our knowledge, such zone classification of antineoplastic agents based on their physicochemical properties to predict risk of permeation through medical gloves has not been reported to date.

Although the zone classification helps appropriately predict permeation risk, Fig. 5 shows several exceptions. First, 5FU exhibited high permeability despite it being plotted on the boundary between Zones A and C. This inconsistent observation may be attributed to its low MW. However, it is necessary to conduct permeation experiments using antineoplastic agents with low $\log \mathrm{P}$ and Low MW to accurately determine the cutoff values. For this purpose, dacarbazine $(\mathrm{MW}=182.18, \log \mathrm{P}=-0.24)$ and melphalan $(\mathrm{MW}=305.02, \log \mathrm{P}=-0.52)$ are potential candidates. Second, DXR had much lower $\mathrm{PR}_{240}$ than ETP and PTX (Fig. 5), despite the MW of DXR (543.5) being lower than that of ETP (588.6) and PTX (853.9). This observation can be explained by assuming that the $\log P$ value of DXR in the test solution was lower than the reported value. For this study, the LogP value of DXR was procured from the interview form [18], in which the $\log P$ value was measured in a buffered solution ( $\mathrm{pH} 7.4$ ), although the $\mathrm{pH}$ of the test solution was 5.0-6.0 [18]. Considering the pKa value of DXR (8.22) [18], it is possible that the actual LogP value of the test solution was lower than the literature value, which may explain the smaller PR240 value of DXR than that of PTX and ETP.

Because the zone classification (Fig. 5) was constructed based on $\mathrm{PR}_{240}$ data obtained under specific conditions (i.e., using nitrile rubber glove with thickness of 0.05 $\mathrm{mm})$, direct application of this zone classification should be limited to predict the permeation risk of antineoplastic agents under similar conditions. However, the addition of theoretical considerations to zone classification may allow us to estimate the permeation risk of various antineoplastic agents through medical gloves of various materials and thicknesses. For example, the permeation risk of antineoplastic agents through nitrile gloves with different thicknesses can be estimated by considering changes in the $\log \mathrm{P}$ and $\mathrm{MW}$ boundaries along with the change in glove thickness. Theoretically, the cutoff values of MW and $\log \mathrm{P}$ would decrease and 
increase, respectively, with an increase in glove thickness. Because most nitrile medical gloves are thicker than $0.05 \mathrm{~mm}$, the permeation risk of an antineoplastic agent is estimated to be minimal unless its physicochemical properties are in the upper left part of Zone A. In addition, the PR values of various antineoplastic agents have been measured using various medical gloves in several reports. Therefore, it seems possible to comprehensively estimate the permeation risk of various antineoplastic agents through medical gloves of various materials and thicknesses by re-organizing the PR values obtained from these reports into a zone classification. Although future validation experiments are necessary, the proposed zone classification will be useful in evaluating the permeation risk of new antineoplastic agents through various medical gloves.

This study has several limitations. First, the permeation experiments in this study were discontinued at $240 \mathrm{~min}$, considering the actual time of handling of antineoplastic agents in clinical settings. As shown in Fig. 1, the PRs of several antineoplastic agents (CPA, ETP, IFM, and PTX) were expected to increase further on prolonging the duration of the permeation experiments. However, we assumed that the possible continuous wearing time of medical gloves in clinical settings would not exceed 240 min; thus, we evaluated the factors that affected the risk of permeation of antineoplastic agents through nitrile medical gloves used only until $240 \mathrm{~min}$. Second, the $\operatorname{LogP}$ values used in this study were obtained from existing literature, and not actually measured in this study. Since the $\log \mathrm{P}$ values are subject to change based on the experimental conditions ( $\mathrm{pH}$ of solution), the LogP values of antineoplastic agents at $\mathrm{pH}$ values similar to those of the test solutions must be measured in future studies. Third, the zone classification shown in Fig. 5 was developed using nitrile medical gloves of $0.05 \mathrm{~mm}$ thickness; therefore, it cannot be directly extrapolated to medical gloves made of different materials and/or of different thicknesses. Since the boundary lines for MW and $\log \mathrm{P}$ would change depending on the material and/or thickness of the medical gloves, the same experiments using the medical gloves of interest should be conducted as necessary.

\section{Conclusion}

MW was confirmed as the crucial determining factor of permeability of antineoplastic agents through nitrile medical gloves within the actual continuous wearing time in clinical settings $(<240 \mathrm{~min})$. Additionally, permeability of antineoplastic agents with high $\operatorname{LogP}$ values (considered highly permeable) could change based on the MW. We believe that the proposed zone classification of antineoplastic agents based on their MW and $\log \mathrm{P}$ values will be useful in predicting the risk of permeability of antineoplastic agents through medical gloves.

\section{Abbreviations}

ASTM: The American Society of Testing and Materials; BCNU: Carmustine;

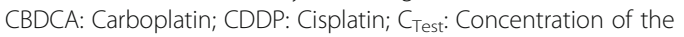
antineoplastic agent in the test solution; $\mathrm{CL}_{\mathrm{p} \text { app: }}$ : Apparent permeation clearance; CPA: Cyclophosphamide; DXR: Doxorubicin; ETP: Etoposide; 5FU: Fluorouracil; IFM: Ifosfamide; LogP: Logarithm of octanol-water partition coefficient; LOQ: Limit of quantitation; MW: Molecular weight;

OXA: Oxaliplatin; PPE: Personal preventive equipment; PR: Permeation rate; $\mathrm{PR}_{240}$ : Permeation rate at 240 min from the start of the permeation experiment; PTX: Paclitaxel; S: Surface area of the glove exposed to an antineoplastic agent.; t: Exposure time; V: Volume of collected receptor solution

\section{Acknowledgements}

We greatly appreciate Shionogi Pharma CO., Ltd. for their contribution in providing the assays of antineoplastic agents. We would also like to thank Editage (www.editage.jp) for English language editing.

\section{Authors' contributions}

TO and TY participated in developing the study design, performed the permeation study and data analysis, and wrote the manuscript; KNara, KNakajima, HS, and TA participated in developing the study design and drafting the manuscript; and YK participated in developing the study design and wrote the manuscript. All authors have read and approved the final manuscript.

\section{Funding}

This work was partially supported by research funding from Okamoto Industries, Inc

\section{Availability of data and materials}

Please contact the corresponding author for data requests.

Ethics approval and consent to participate

Not applicable.

\section{Consent for publication}

Not applicable.

\section{Competing interests}

KNakajima received research funding for this study from Okamoto Industries, Inc. The other authors have no competing interests to declare.

\section{Author details}

${ }^{1}$ Tokyo University of Science, Faculty of Pharmaceutical Sciences, 2641 Yamazaki, Noda, Chiba 278-8510, Japan. ²Department of Pharmacy, The University of Tokyo Hospital, Faculty of Medicine, The University of Tokyo, 7-3-1 Hongo, Bunkyo-ku, Tokyo 113-8655, Japan. ${ }^{3}$ The Education Center for Clinical Pharmacy, Graduate School of Pharmaceutical Sciences, The University of Tokyo, 7-3-1 Hongo, Bunkyo-ku, Tokyo 113-0033, Japan.

Received: 22 July 2020 Accepted: 29 September 2020

Published online: 02 November 2020

References

1. Sorsa M, Hemminki K, Vainio H. Occupational exposure to anticancer drug-potential and real hazards. Mutat Res. 1985;154:135-49.

2. Stellman JM, Zoloth SR. Cancer chemotherapeutic agents as occupational hazards: a literature review. Cancer Investig. 1986;4:127-35.

3. Burgaz S, Karahalil B, Bayrak P, Taskin L, Yavuzaslan F, Bokesoy I, et al. Urinary cyclophosphamide excretion and micronuclei frequencies in peripheral lymphocytes and in exfoliated buccal epithelial cells of nurses handling antineoplastics. Mutat Res. 1999;439:97-104.

4. Harrison B. Risks of handling cytotoxic drugs. In: Perry MC, editor. The chemotherapy source book. 3rd ed. Philadelphia: Williams \& Wilkins; 2001. p. 566-80.

5. Norppa H, Sorsa M, Vainio H, Grohn P, Heinonen E, Holsti L, et al. Increased sister chromatid exchange frequencies in lymphocytes of nurses handling cytostatic drugs. Scand J Work Environ Health. 1980;6:299-301. 
6. Sasaki M, Dakeishi M, Hoshi S, Ishii N, Murata K. Assessment of DNA damage in Japanese nurses handling antineoplastic drugs by the comet assay. J Occup Health. 2008;50:7-12.

7. Power LA, Coyne JW. ASHP guidelines on handling hazardous drugs. Am J Health Syst Pharm. 2018;75:1996-2031.

8. Guideline for Aseptic Preparation of Injectable and Antineoplastic Drugs. Japanese society of hospital pharamacists, ed. Tokyo: YakujiNippo Ltd.; 2008. p27-8.

9. In-hospital Antineoplastic Drug Handling Guidelines: Anticancer Drug Preparation Manual, 4th ed.: Anticancer Drug Preparation Manual. Japanese society of hospital pharamacists, ed. Tokyo: Jiho Inc, 2019. p13-5.

10. Safe handling of hazardous drugs. 3rd ed. Polovinch M, Olsen M, Pittsburgh: Oncology Nursing Society; 2018. p25-7.

11. ASHP guidelines on compounding sterile preparations. Am J Health Syst Pharm. 2014:71:145-66.

12. Wallemacq PE, Capron A, Vanbinst R, Boeckmans E, Gillard J, Favier B. Permeability of 13 different gloves to 13 cytotoxic agents under controlled dynamic conditions. Am J Health Syst Pharm. 2006;63:547-56.

13. Klein M, Lambov N, Samev N, Carstens G. Permeation of cytotoxic formulations through swatches from selected medical gloves. Am J Health Syst Pharm. 2003;60:1006-11.

14. Oriyama T, Yamamoto T, Yanagihara Y, Nara K, Abe T, Nakajima K, et al. Evaluation of the permeation of antineoplastic agents through medical gloves of varying materials and thickness and with varying surface treatments. J Pharm Health Care Sci. 2017;3:13.

15. ASTM International. ASTM D6978-05: Standard practice for assessment of resistance of medical gloves to permeation by chemotherapy drugs; 2013. https://www.astm.org/Standards/D6978.htm. Accessed 8 Aug 2020.

16. U.S. Environmental Protection Agency. Carboplatine, PROPERTIES. https:// comptox.epa.gov/dashboard/dsstoxdb/results?search=DTXSID3046742 \#properties. Accessed 21 Apr 2020.

17. Exploring QSAR: Hydrophobic, electronic, and steric constants. Hansch C, Leo A, Hoekman D. Washington DC: American Chemical Society; 1995.

18. ADRIACIN ${ }^{\otimes}$ Injection Interview Form. 18th ed. Aspen Japan K. K.; 2017.

19. 5-FU Injection $250 \mathrm{Kyy}^{\circledR}{ }^{\circledR}$ Interview Form. 7th ed. Kyowa Kirin Co., Ltd; 2019.

20. Ifomide Interview Form. 3rd ed. Shionogi \& Co., Ltd.; 2012

21. ELPLAT I.V.INFUSION SOLUTION Interview Form. 15th ed. Yakult Honsha Co., Ltd.; 2020

22. TAXOL ${ }^{\oplus}$ NJECTION Interview Form. 10th ed. Bristol-Myers Squibb K.K; 2018.

23. ASTM F739-07: Standard Test Method for Permeation of Liquids and Gases through Protective Clothing Materials under Conditions of Continuous Contact. 2007. https://www.astm.org/Standards/F739.htm. Accessed 8 Aug 2020.

24. U.S. Environmental Protection Agency. tert-Butyl alcohol, PROPERTIES. https://comptox.epa.gov/dashboard/dsstoxdb/results?search=tert-butanol. Accessed 21 Apr 2020

25. Phalen RN, Dubrovskiy AV, Brown BC, Gvetadze AR, Bustillos M, Ogbonmwan J. Chemical permeation of similar disposable nitrile gloves exposed to volatile organic compounds with different polarities part 2. Predictive polymer properties. J Occup Environ Hyg. 2020;17:172-80.

\section{Publisher's Note}

Springer Nature remains neutral with regard to jurisdictional claims in published maps and institutional affiliations.

Ready to submit your research? Choose BMC and benefit from:

- fast, convenient online submission

- thorough peer review by experienced researchers in your field

- rapid publication on acceptance

- support for research data, including large and complex data types

- gold Open Access which fosters wider collaboration and increased citations

- maximum visibility for your research: over $100 \mathrm{M}$ website views per year

At BMC, research is always in progress.

Learn more biomedcentral.com/submissions 